\title{
CHARACTERISTICS OF DROPLETS GENERATED BY BUBBLE BURSTING FROM CHROMIC ACID SOLUTIONS
}

\author{
Y. M. Kuo* and C. S. Wang ${ }^{\dagger \ddagger}$ \\ * Graduate Institute of Environmental Health, National Taiwan University, 100 Taipei, Taiwan \\ ${ }^{\dagger}$ Department of Public Health, National Taiwan University, 100 Taipei, Taiwan
}

(First received 26 June 1998; and in final form 21 December 1998)

\begin{abstract}
The effects of electrolyte concentration and gas flow rate on the characteristics of droplets generated from bubbles bursting on the surface of $\mathrm{CrO}_{3}$ solution were studied with an experimental bubbling system. The experimental conditions included two electrolyte concentrations, 125 and $250 \mathrm{gl}^{-1}$ of $\mathrm{CrO}_{3}$, and three flow rates of sparging air in the range of $4-81 \mathrm{~min}^{-1}$. A cascade impactor collected droplet samples for chemical analysis. A laser aerosol spectrophotometer and an aerodynamic particle sizer were employed simultaneously to measure the number concentration and size distribution of the droplets. A layer of foam formed on the liquid surface under all experimental conditions studied except at the gas flow rate of $41 \mathrm{~min}^{-1}$ in $125 \mathrm{gl}^{-1} \mathrm{CrO}_{3}$ solution. Foams had a significant effect on the characteristics of droplets generated from bursting bubbles. At identical gas flow rate and electrolyte concentration, the formation of foams led to a reduction in number concentration of droplets larger than $10 \mu \mathrm{m}$ in aerodynamic diameter and a lower concentration of airborne $\mathrm{Cr}(\mathrm{VI})$. In the ranges of gas flow rate and electrolyte concentration tested, the results showed that the airborne $\mathrm{Cr}(\mathrm{VI})$ mass concentration increased significantly with gas flow rate and slightly with electrolyte concentration in the presence of foams. The results obtained in the present study should have applications in the emission control of $\mathrm{Cr}(\mathrm{VI})$-containing droplets in chromium electroplating processes. (C) 1999 Elsevier Science Ltd. All rights reserved
\end{abstract}

\section{INTRODUCTION}

The generation of droplets from single bubbles bursting on a liquid surface involves two distinct mechanisms: breakage of droplet film and formation of liquid jet. When a gas bubble produced in the bulk of an electrolyte solution rises to the surface, it forms a hemispheric film cap above the liquid surface. The film cap becomes thinner because of liquid drainage and breaks into numerous minute droplets when its thickness reaches a certain critical value. The droplets, named film droplets, vary from submicrometer to $20 \mu \mathrm{m}$ in diameter (Garner et al., 1954). Immediately following the breakage of a bubble, the surrounding liquid fills the remaining bubble cavity and a liquid jet appears in the center of the crater. Jet droplets are produced from breakup of the jet rising upward from the collapsing bubble cavity. In general, jet droplets are about ten times larger than film droplets (Newitt et al., 1954).

In many natural and industrial processes involving gas bubbling in liquids, bubbles that have reached the liquid surface may not burst immediately. These bubbles may randomly float around, coalesce into larger bubbles, or attach to each other and form rafts of bubbles or a layer of foam. The characteristics of droplets generated from single bubbles bursting in the absence of a foam may differ considerably from those generated from bursting of multiple bubbles in a foam layer. When the liquid surface is covered with a layer of foam, droplets formed solely from rupture of foam film in a manner similar to the generation of droplets from rupture of the film cap of a single bubble but no jet droplets are produced (Garner et al., 1954; Van Dusen and Smith, 1989; Hinds and Kuo, 1990).

Gas bubbling in electrolyte solutions is a common phenomenon in electroplating processes. In Taiwan, $\mathrm{Cr}(\mathrm{VI})$-containing droplets generated in chromium electroplating processes have received considerable attention because of high prevalence rates of nasal septum ulcer or perforation among chromium electroplating workers (Lin et al., 1994).

\footnotetext{
${ }^{\ddagger}$ Author to whom correspondence should be addressed.
} 
$\mathrm{Cr}(\mathrm{VI})$-containing compounds are highly toxic and carcinogenic. Epidemiological studies indicate that $\mathrm{Cr}(\mathrm{VI})$-containing droplets are probably the main cause for nasal septum disorders and lung cancer among chromium electroplating workers (Langard, 1990; Sanz et al., 1989). As products of electrochemical reactions, both hydrogen and oxygen gases evolve at the electrodes during chromium electroplating processes. The gas bubbles rise to the liquid surface and burst. As a result, $\mathrm{Cr}(\mathrm{VI})$-containing droplets are formed. The chromium electroplating process has a very low current efficiency, about $80-90 \%$ of the applied current being used to dissociate water and release gases (Burgess, 1995). Moreover, aeration techniques are commonly adopted to enhance current efficiency and to lower the temperature of electrolyte solution in chromium electroplating tanks.

Information on the characteristics of $\mathrm{Cr}(\mathrm{VI})$-containing droplets is needed in the assessment of health effects and the control of $\mathrm{Cr}(\mathrm{VI})$ emissions. The size of droplets determines which regions of lungs they may deposit. In addition, size distribution data on $\mathrm{Cr}(\mathrm{VI})$ containing droplets are useful in selecting effective methods to control the emissions of $\mathrm{Cr}(\mathrm{VI})$.

An interesting aspect of the bursting of single or multiple bubbles is the transfer of chemicals from liquid to air via droplet generation. Much work has been conducted on the transfer of chemicals from sea water or diluted solutions to air. Some of these studies showed that oceanic droplets are enriched with trace metals such as $\mathrm{Fe}, \mathrm{Cu}$, and $\mathrm{Zn}$ (see, for example, Blanchard, 1974; Piotrowicz et al., 1979; Van Grieken et al., 1974). Little is known regarding the transfer of chemicals from concentrated solutions to air by the bursting of bubbles.

This study has the objective of evaluating the effects of $\mathrm{CrO}_{3}$ concentration and gas flow rate on the characteristics of droplets released from bubbles bursting on the liquid surface in an experimental system. The characteristics of droplets studied include the $\mathrm{Cr}(\mathrm{VI})$ concentration in droplets, droplet number concentration and size distribution, and airborne $\mathrm{Cr}(\mathrm{VI})$ concentration.

\section{EXPERIMENTAL APPARATUS AND METHODS}

Figure 1 shows a schematic diagram of the experimental system. The apparatus consisted of a glass cylindrical tank, a water bath, a bubbling system, and the droplet sampling/measuring instruments. The cylindrical tank, $30 \mathrm{~cm}$ in diameter, was sufficiently large that the wall effect on the size of bubbles being produced can be neglected. The tank was put in a water bath to keep the liquid at a constant temperature. In this study, the temperature

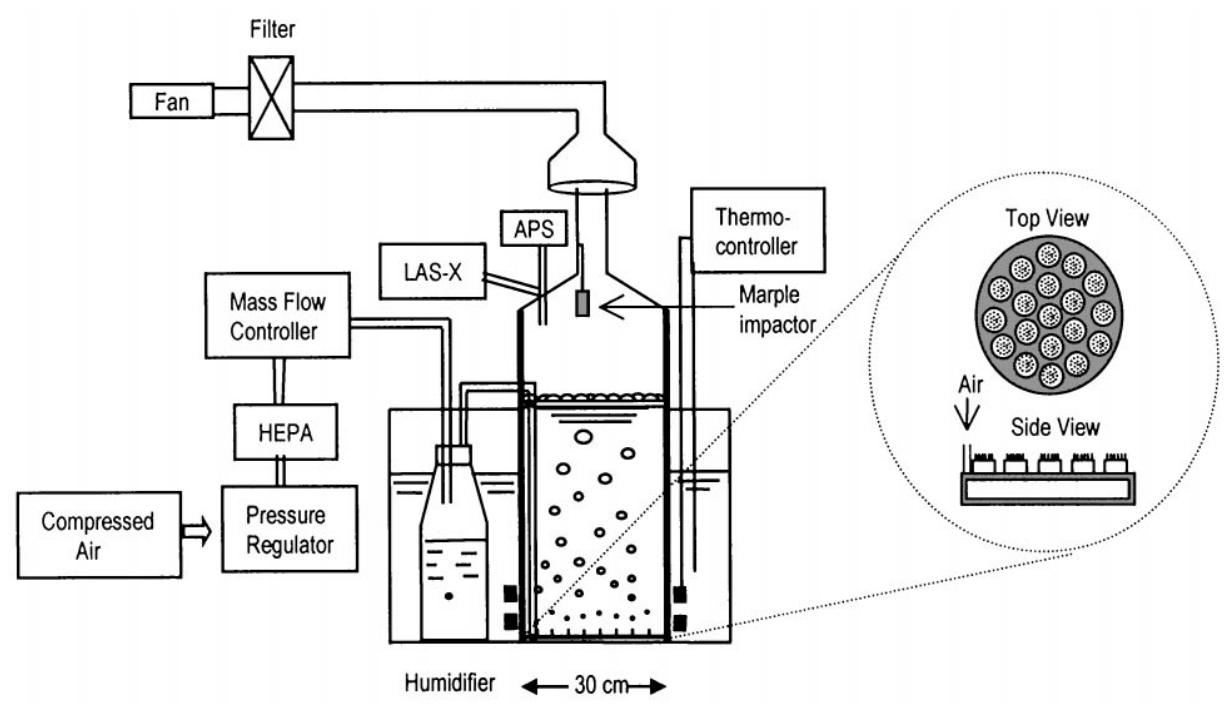

Fig. 1. A schematic diagram of the experimental system. 
of the liquid was maintained at $45^{\circ} \mathrm{C}$ because the temperature of electroplating solutions in practical applications is in the range of $40-50^{\circ} \mathrm{C}(\mathrm{Zaki}, 1990)$. The outer wall of the tank was covered with a thermal jacket and, as a result, the air temperature inside the tank was about $37^{\circ} \mathrm{C}$. Owing to the temperature difference between the liquid and the air, the humidity inside the tank was near saturation during the experiments.

The bubbling system consisted of 19 circular caps, each containing 19 glass capillaries of $0.2 \mathrm{~mm}$ in inner diameter and $3.2 \mathrm{~cm}$ in length. The system was similar to that used by Wangwongwatana et al. (1990) and Pilacinski et al. (1990). Sparging air through the $\mathrm{CrO}_{3}$ solution in the tank led to the formation of droplets above the liquid surface. The sparging air was obtained from a laboratory air supply and its flow rate was controlled by a mass flow controller. The air passed through a HEPA filter and a humidifier before entering the bubbling system. The sizes of bubbles generated in the system were comparable to those in chromium electroplating processes.

To measure the $\mathrm{Cr}(\mathrm{VI})$ concentration in the droplets, a Marple personal cascade impactor (Model 290, Graseby Andersen, Atlanta, GA, U.S.A.) was used to collect droplets on polyvinyl chloride filters (PVC filters, $34 \mathrm{~mm}, 5 \mu \mathrm{m}$ pore size, Omega Specialty Instrument Co., Chelmsford, MA, U.S.A.). The impactor has eight stages with aerodynamic cutoff diameters of $0.6,1,1.5,3.5,6,10,15,21 \mu \mathrm{m}$ at a sampling flow rate of $21 \mathrm{~min}^{-1}$. Droplets of different size ranges were collected on PVC filters and the $\mathrm{Cr}(\mathrm{VI})$ concentrations of the samples were determined by chemical analysis. The impactor was placed at $35 \mathrm{~cm}$ above the liquid surface.

Two real-time aerosol instruments, a laser aerosol spectrometer (Model LAS-X, Particle Measuring Systems Inc., Boulder, CO, U.S.A.) and an aerodynamic particle sizer (APS, Model 3310, TSI, St. Paul, MN, U.S.A.) were employed to determine the size distribution of droplets which had a broad size range covering the sizes of both film and jet droplets. The aerosol sampling flow rates of a LAS-X and an APS are 0.3 and $11 \mathrm{~min}^{-1}$, respectively. The sampling probes of these two instruments were placed side by side above the liquid at the same height as that of the impactor.

Two concentrations of electrolyte solution commonly applied in electroplating processes, 125 and $250 \mathrm{~g}^{-1} \mathrm{CrO}_{3}$, were used in this study. In each run, the electrolyte solution was first heated to $45^{\circ} \mathrm{C}$ in a storage container. Filtered and humidified air was then introduced into the bubbling system at a selected flow rate. In the meantime, the electrolyte solution was gradually transferred to the glass cylindrical tank by a peristaltic pump (Model 505S, Watson Marlow, Falmouth, U.K.). The production of droplets was found to reach a steady state in about $2 \mathrm{~h}$. Airborne droplets were sampled by an impactor for a duration of $4 \mathrm{~h}$ after the air had been bubbling for $2 \mathrm{~h}$. The U.S. National Institute for Occupational Safety and Health (NIOSH) method 7600 was employed to determine the $\mathrm{Cr}(\mathrm{VI})$ concentration of each droplet sample. The method utilizes the reagent $s$-diphenylcarbazide which reacts specifically with $\mathrm{Cr}(\mathrm{VI})$ to form a purple-red color complex. Each droplet sample was extracted by $0.5 \mathrm{~N} \mathrm{H}_{2} \mathrm{SO}_{4}$ solution and the extract solution was diluted to a volume of $5 \mathrm{ml}$. The absorbance of the color complex at $540 \mathrm{~nm}$ was measured by using a UV-VIS recording spectrophotometer with a light path of $1 \mathrm{~cm}$ (Model UV-160A, Shimadzu Corporation, Japan). The detection limit was $1.8 \mathrm{ng} \mathrm{ml}^{-1}$ (equivalent to $19 \mathrm{ng} \mathrm{m}^{-3}$ for a $480-\mathrm{L}$ air sample). In each run, the number concentration and size distribution of the droplets were measured several times by a LAS-X and an APS simultaneously. Three runs were made for each set of experimental conditions.

\section{RESULTS AND DISCUSSION}

During the bubbling process, rafts of bubbles or a layer of foam appeared on the liquid surface under most experimental conditions. The foam height was determined with a ruler by observing the top edge of foam film and the interface between the foam and the bulk solution on the wall of the glass tank. The foam height after bubbling for $2 \mathrm{~h}$ was recorded because the foam was found to stabilize at that time by visual inspection. A layer of foam formed on the liquid surface under all experimental conditions studied except at the gas 
flow rate of $41 \mathrm{~min}^{-1}$ in $125 \mathrm{~g}^{-1} \mathrm{CrO}_{3}$ solution. The foam height ranged from 0.6 to $1.2 \mathrm{~cm}$ as the gas flow rate varied from 4 to $81 \mathrm{~min}^{-1}$. The height of the foam increased with gas flow rates as was reported by Pilacinski et al. (1990). The formation of foam was caused by the presence of a critical amount of unidentified surfactants which tended to accumulate after the electrolyte solution had been reused a number of times.

\section{Effects of gas flow rate and electrolyte concentration on airborne $\mathrm{Cr}(\mathrm{VI})$ concentration}

Figure 2 presents the effects of gas flow rate and electrolyte concentration on airborne $\mathrm{Cr}(\mathrm{VI})$ concentration in droplets larger than $0.6 \mu \mathrm{m}$ in aerodynamic diameter sampled by an impactor. In the presence of a foam layer, airborne $\mathrm{Cr}(\mathrm{VI})$ concentration was proportional to gas flow rate but was relatively insensitive to changes in electrolyte concentration. For example, airborne $\mathrm{Cr}(\mathrm{VI})$ concentration ranged from 0.7 to $10.3 \mu \mathrm{g} \mathrm{m}^{-3}$ as the gas flow rate varied from 4 to $81 \mathrm{~min}^{-1}$ in $250 \mathrm{~g}^{-1} \mathrm{CrO}_{3}$ solution. However, at the same gas flow rate of $81 \mathrm{~min}^{-1}$, only a small difference of $0.9 \mu \mathrm{g} / \mathrm{m}^{3}$ in airborne $\mathrm{Cr}(\mathrm{VI})$ concentration was found between 125 and $250 \mathrm{gl}^{-1} \mathrm{CrO}_{3}$ solutions. The airborne $\mathrm{Cr}(\mathrm{VI})$ concentration was significantly higher when the liquid surface was only partially covered with bubbles (see the first solid bar in Fig. 2).

Figure 3 compares the $\mathrm{Cr}(\mathrm{VI})$ mass size distributions of droplets determined under six sets of experimental conditions. In the presence of a foam layer, the airborne $\mathrm{Cr}(\mathrm{VI})$ concentration of droplets in the measured size range of $0.6-30 \mu \mathrm{m}$ was higher in smaller droplets. However, there was a peak at a droplet size larger than $15 \mu \mathrm{m}$ when no foam layer was formed. The foam appears to prevent the formation of droplets larger than about $10 \mu \mathrm{m}$ in aerodynamic diameter. This may explain why the airborne $\mathrm{Cr}(\mathrm{VI})$ concentrations obtained at the same gas flow rate of $41 \mathrm{~min}^{-1}$ differ markedly between the two electrolyte concentrations (see the first group of Fig. 3).

\section{Effects of gas flow rate and electrolyte concentration on droplet concentration}

To determine the droplet number concentration and size distribution, the size range of $0.1-0.75 \mu \mathrm{m}$ in optical diameter was measured by a LAS-X and the size range of $0.75-30 \mu \mathrm{m}$ in aerodynamic diameter was measured by an APS, simultaneously. The LAS-X utilizes a laser as a light source and detects the optical diameter of a particle. The APS measures the aerodynamic diameter by accelerating a particle through a nozzle and measuring the time it takes to pass through two closely spaced laser beams. Figure 4 compares the number size distributions of droplets produced at various gas flow rates and electrolyte concentrations. The droplets were mainly in the submicrometer range, regardless of the presence or absence of foams.

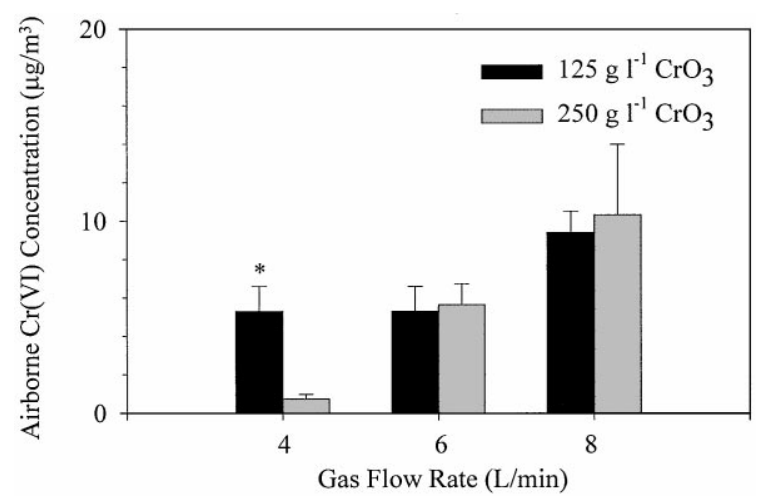

Fig. 2. Airborne $\mathrm{Cr}(\mathrm{VI})$ concentrations in droplets larger than $0.6 \mu \mathrm{m}$ aerodynamic size range determined by a Marple personal cascade impactor without backfilter at gas flow rates of 4, 6, and $81 \mathrm{~min}^{-1}$. The error bar represents one standard deviation from three measurements. ${ }^{*}$ No foam was formed. 


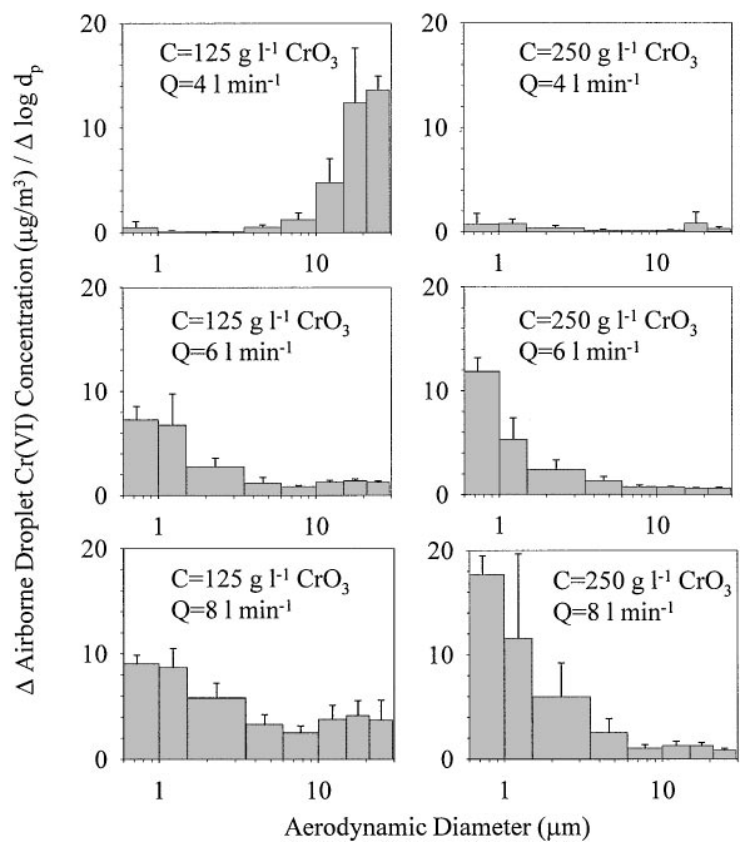

Fig. 3. Airborne $\mathrm{Cr}(\mathrm{VI})$ mass distributions in droplets of $0.6-30 \mu \mathrm{m}$ aerodynamic size range determined by a Marple personal cascade impactor at different combinations of electrolyte concentration and gas flow rate. The error bar represents one standard deviation from three measurements.

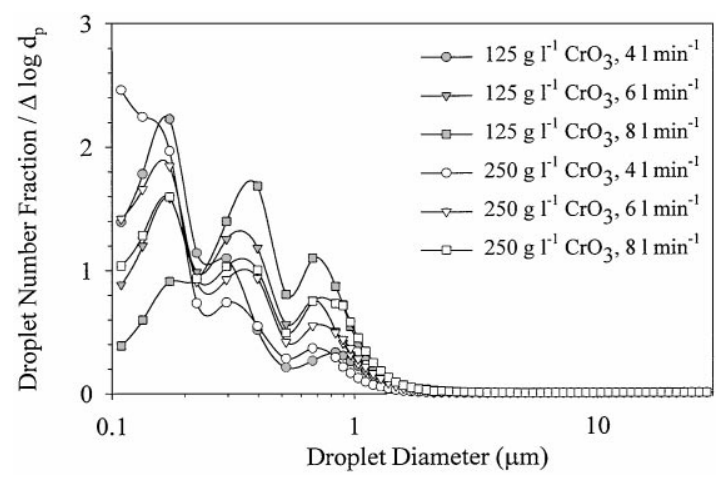

Fig. 4. Comparison of airborne droplet number size distributions in the size range of $0.1-30 \mu \mathrm{m}$ measured by a LAS-X and an APS at gas flow rates of 4, 6, and $81 \mathrm{~min}^{-1}$ and electrolyte concentrations of 125 and $250 \mathrm{~g} \mathrm{l}^{-1} \mathrm{CrO}_{3}$. (Optical diameter is used for $<0.75 \mu \mathrm{m}$ and aerodynamic diameter is used for $>0.75 \mu \mathrm{m})$.

Table 1 shows the droplet number concentrations in the measured size range of 0.1-30 $\mu \mathrm{m}$ under the six sets of experimental conditions. Also shown in the table are the droplet volume concentrations calculated from the droplet number concentration data. The droplet volume concentration in a given size interval was obtained by multiplying the volume of a droplet with the geometric mean diameter by the number concentration in a given size interval $\left(\pi d_{\mathrm{g}}^{3} N / 6\right.$, where $d_{\mathrm{g}}$ is the geometric mean diameter and $N$ the number concentration of droplets in a given size range). In the presence of a foam layer, the number concentration of droplets increased with gas flow rate and reached a maximum at a gas flow rate higher than $61 \mathrm{~min}^{-1}$, whereas the change in electrolyte concentration had little influence on droplet number concentration. At a gas flow rate of $41 \mathrm{~min}^{-1}$ in $125 \mathrm{gl}^{-1}$ $\mathrm{CrO}_{3}$ solution, no foam was formed and the droplet concentration was higher than those under other experimental conditions. 
Table 1. Summary of number concentrations and volume concentrations of droplets generated from various gas flow rates and electrolyte concentrations

\begin{tabular}{llccc}
\hline $\mathrm{CrO}_{3}\left(\mathrm{~g}^{-1}\right)$ & 4 & 6 & 8 \\
\hline 125 & Flow rate $\left(1 \mathrm{~min}^{-1}\right)$ & $4.830 \pm 420^{*}$ & $2.610 \pm 670$ & $2.690 \pm 20$ \\
& Number concentration $\left(\# \mathrm{~cm}^{-1}\right)$ & $475 \pm 121^{*}$ & $282 \pm 92$ & $511 \pm 128$ \\
250 & Volume concentration $\left(\mu \mathrm{m}^{3} \mathrm{~cm}^{-3}\right)$ & $1.640 \pm 340$ & $2.450 \pm 810$ & $2.450 \pm 270$ \\
& Number concentration $\left(\# \mathrm{~cm}^{-3}\right)$ & $79 \pm 45$ & $226 \pm 84$ & $379 \pm 97$ \\
\hline
\end{tabular}

* No foam was formed.

Table 2. Summary of count median diameter (CMD) and volume median diameter $(V M D)$ of droplets generated from various gas flow rates and electrolyte concentrations

\begin{tabular}{lllll}
\hline $\mathrm{CrO}_{3}\left(\mathrm{~g}^{-1}\right)$ & Flow rate $\left(1 \mathrm{~min}^{-1}\right)$ & 4 & 6 & 8 \\
\hline 125 & $\mathrm{CMD}(\mu \mathrm{m})$ & $0.19^{*}$ & 0.26 & 0.35 \\
& $V M D(\mu \mathrm{m})$ & $1.93^{*}$ & 1.21 & 1.40 \\
250 & $\mathrm{CMD}(\mu \mathrm{m})$ & 0.17 & 0.20 & 0.25 \\
& $V M D(\mu \mathrm{m})$ & 1.13 & 1.15 & 1.28 \\
\hline
\end{tabular}

* No foam was formed.

The droplet volume concentration increased with increasing gas flow rate and decreasing electrolyte concentration in the presence of a foam layer. This is in good agreement with the experimental results reported by Gleim et al. (1966). Under the conditions of $125 \mathrm{~g}^{-1} \mathrm{CrO}_{3}$ solution and a gas flow rate of $61 \mathrm{~min}^{-1}$, the droplet volume concentration reached a minimum with respect to gas flow rate because of the suppression effect of foam on the production of large droplets.

Table 2 is a summary of count median diameter (CMD) and volume median diameter (VMD) calculated from the size distribution data measured by the LAS-X and the APS. The CMDs of the droplets varied from 0.17 to $0.35 \mu \mathrm{m}$ and the VMDs of the droplets were slightly higher than $1 \mu \mathrm{m}$. In general, an increasing tendency with gas flow rate and a decreasing tendency with electrolyte concentration were observed for both CMD and VMD in the presence of a foam layer. The droplets generated in the absence of a foam layer had a higher VMD than those generated in the presence of foams.

\section{Effect of foam formation on the characteristics of droplets}

In the absence of a foam layer, the bursting of bubbles generally produce a higher airborne $\mathrm{Cr}(\mathrm{VI})$ concentration and droplet concentration than in the presence of foams, as indicated in Fig. 2 and Table 1. Figures 5 and 6 illustrate the effect of foam formation on the characteristics of droplets. The experimental conditions were $81 \mathrm{~min}^{-1}$ gas flow rate in $125 \mathrm{gl}^{-1} \mathrm{CrO}_{3}$ solution for the results shown in Figs 5(A) and 6(A) and $41 \mathrm{~min}^{-1}$ gas flow rate in $250 \mathrm{gl}^{-1} \mathrm{CrO}_{3}$ solution for the results in Figs 5(B) and 6(B).

Figure 5 shows the effect of foam on the droplet $\mathrm{Cr}(\mathrm{VI})$ mass distribution determined by an impactor for air bubbling at $81 \mathrm{~min}^{-1}$ in $125 \mathrm{gl}^{-1} \mathrm{CrO}_{3}$ solution and at $41 \mathrm{~min}^{-1}$ in $250 \mathrm{gl}^{-1}$ electrolyte solution. In both cases, it was observed that the foam layer suppressed the formation of larger droplets and therefore reduced the total airborne $\mathrm{Cr}(\mathrm{VI})$ concentration.

Figure 6 presents the effect of foam on droplet volume concentrations which were calculated from the droplet number concentration data obtained by a LAS-X and an APS. The droplet volume distributions were bimodal in the absence of foam, with one peak at about $1 \mu \mathrm{m}$ and another around $10 \mu \mathrm{m}$. The formation of foam prevented the production of larger droplets as seen in both Figs 5 and 6. This finding is similar to that observed by Garner et al. (1954), Van Dusen and Smith (1989) and Hinds and Kuo (1990). 


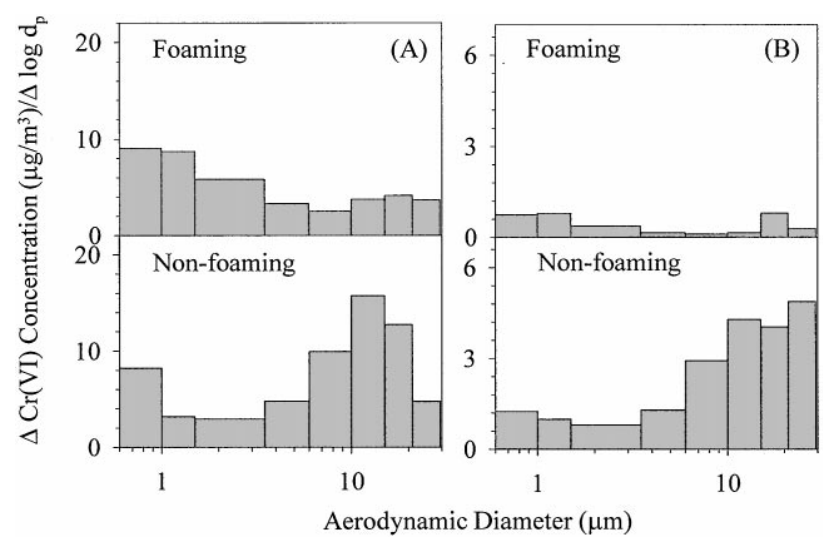

Fig. 5. The effect of foam formation on airborne $\mathrm{Cr}(\mathrm{VI})$ mass distributions in droplets determined by a Marple personal cascade impactor. (Experimental conditions: (A) $125 \mathrm{gl}^{-1} \mathrm{CrO}_{3}$, flow rate $81^{-1}$ (B) $250 \mathrm{gl}^{-1} \mathrm{CrO}_{3}$, flow rate $41 \mathrm{~min}^{-1}$.)

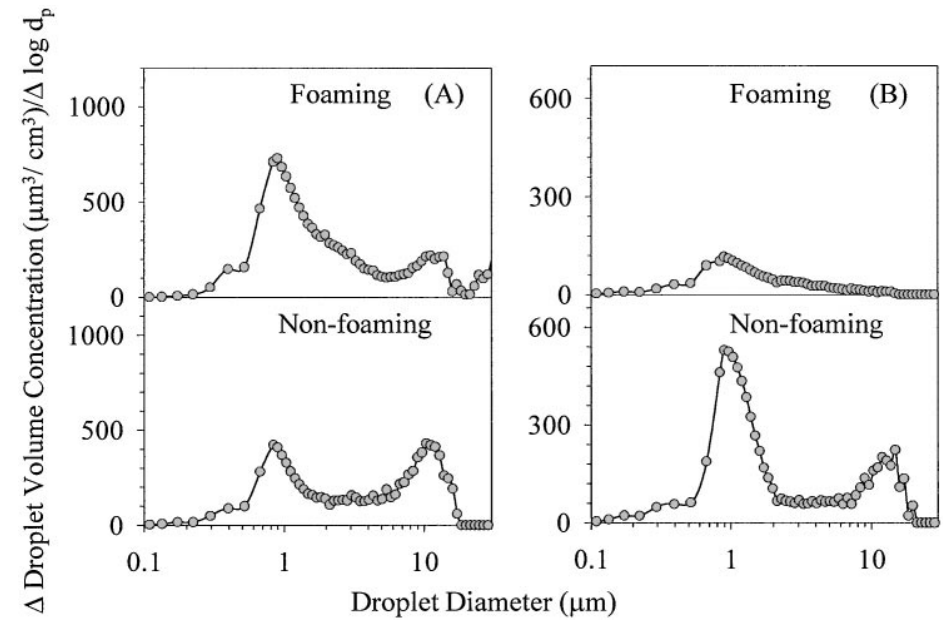

Fig. 6. The effect of foam formation on airborne droplet volume concentrations calculated from the number concentration data measured by a LAS-X and an APS. (Experimental conditions: (A) $125 \mathrm{~g} \mathrm{l}^{-1} \mathrm{CrO}_{3}$, flow rate $81 \mathrm{~min}^{-1}$; (B) $250 \mathrm{gl}^{-1} \mathrm{CrO}_{3}$, flow rate $41 \mathrm{~min}^{-1}$, optical diameter for $<0.75 \mu \mathrm{m}$, aerodynamic diameter for $>0.75 \mu \mathrm{m})$.

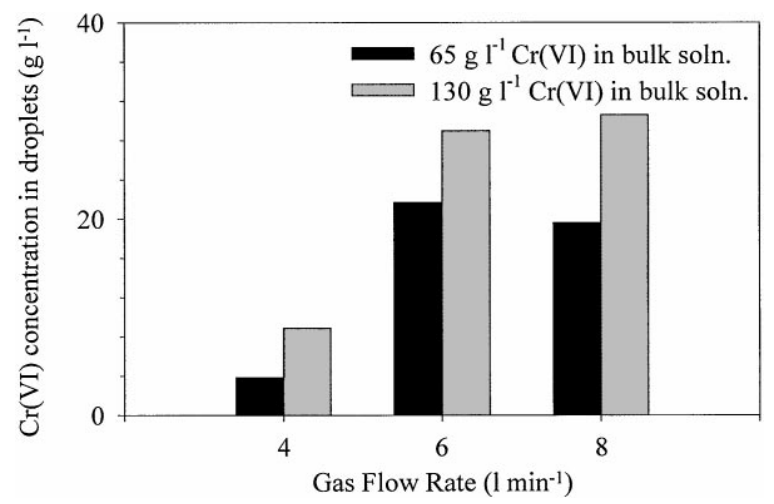

Fig. 7. Estimated $\mathrm{Cr}(\mathrm{VI})$ concentrations in droplets of $0.6-10 \mu \mathrm{m}$ size range in aerodynamic diameter at gas flow rates of 4,6 and $81 \mathrm{~min}^{-1}$.

\section{Estimated $C r(V I)$ concentration in droplets}

Figure 7 shows the estimated $\mathrm{Cr}(\mathrm{VI})$ concentrations in droplets of $0.6-10 \mu \mathrm{m}$ in aerodynamic diameter. The $\mathrm{Cr}(\mathrm{VI})$ concentration in droplets was determined by dividing the 
total Cr(VI) mass in droplets (see Fig. 2) by the total droplet volume calculated from the measured droplet number concentration.

In general, the $\mathrm{Cr}(\mathrm{VI})$ concentration in droplets varied from about 4 to $30 \mathrm{~g} 1^{-1}$. The $\mathrm{Cr}(\mathrm{VI})$ concentration in droplets tended to reach a maximum as the gas flow rate increased. Increasing $\mathrm{Cr}(\mathrm{VI})$ concentration of bulk solution had little influence on the $\mathrm{Cr}(\mathrm{VI})$ concentration in droplets. Under the six sets of experimental conditions, the $\mathrm{Cr}(\mathrm{VI})$ concentration in droplets in each size range was lower than that in the bulk solution. This was mainly a result of the condensation of water vapor onto the droplets in the air above the heated solution in the bubbling system.

\section{CONCLUSIONS}

In this study, two concentrations of chromic acid solution, 125 and $250 \mathrm{gl}^{-1} \mathrm{CrO}_{3}$, and three sparging gas flow rates, 4, 6 and $81 \mathrm{~min}^{-1}$, were employed to conduct the experiments. A layer of foam was formed on the liquid surface under all the experimental conditions except at a gas flow rate of $41 \mathrm{~min}^{-1}$ in $125 \mathrm{gl}^{-1} \mathrm{CrO}_{3}$ solution. In the presence of a foam layer, the airborne $\mathrm{Cr}(\mathrm{VI})$ mass concentration increased markedly with gas flow rate and slightly with electrolyte concentration. The droplets were mainly in the submicrometer range with a CMD range of $0.17-0.35 \mu \mathrm{m}$ under all the experimental conditions studied. The CMD of droplets increased with increasing gas flow rate and decreasing electrolyte concentration. The droplet number concentration increased first with gas flow rate and approached a maximum in the presence of foam. Moreover, the $\mathrm{Cr}(\mathrm{VI})$ concentration in droplets was markedly lower than that in bulk solution. In the absence of a foam layer, the airborne $\mathrm{Cr}(\mathrm{VI})$ concentration in droplets larger than $10 \mu \mathrm{m}$ aerodynamic diameter was higher than that in the presence of foams.

Field studies on the characteristics of $\mathrm{Cr}(\mathrm{VI})$-containing droplets and airborne $\mathrm{Cr}(\mathrm{VI})$ concentrations in chromium electroplating plants (see, for example, Lin et al., 1994; Kuo et al., 1997), in general, did not examine the effect of factors such as gas flow rate and the electrolyte concentration. The results on the effects of gas flow rate and electrolyte concentration obtained in the present study should have applications in the control of $\mathrm{Cr}(\mathrm{VI})$ containing droplets in chromium electroplating processes. For example, the $\mathrm{Cr}(\mathrm{VI})$ emission rate can be reduced by lowering the gas flow rate. The airborne $\mathrm{Cr}(\mathrm{VI})$ concentration, especially in larger droplets, can also be reduced through the formation of a foam layer by adding some surfactants.

Acknowledgements - This study was supported in part by the Taiwan National Science Council Grant No. NSC 87-2211-E-002-015. Y. M. Kuo was supported by a stipend for graduate education awarded by the same grant of the Taiwan National Science Council during part of her Ph.D. study. The authors are grateful to Dr. C. C. Chen for his helpful suggestions in designing the experimental system and using the real-time aerosol instruments.

\section{REFERENCES}

Blandchard, D. C. (1974) International symposium on the chemistry of sea/air particulate exchange processes: summary and recommendations. J. Rech. Atmos. 8, 509-513.

Burgess, W. A. (1995) Recognition of Health Hazards in Industry: A Review of Materials and Processes, 2nd Edition, pp. 227-240. Wiley, New York.

Garner, F. H., Ellis, S. R. M. and Lacey, J. A. (1954) The size distribution and entrainment of droplets. Trans. Instn. Chem. Engrs. 32, 222-235.

Gleim, V. G., Shidlovskii, B. R., Vishnevetskaya, A. N. and Khentov, V. YA. (1966) Investigation of drop entrainment during microbubbling. J. Appl. Chem. U.S.S.R. 39, 70-74.

Hinds, W. C. and Kuo, T. L. (1990) Role of liquid properties on droplet formation by bursting bubbles. In Proc. 3rd Int. Aerosol Conf., (Edited by Masuda, S. and Takahashi, K.), pp. 251-254. Kyoto, Japan.

Kuo, H. W., Lai, J. S. and Lin, T. I. (1997) Concentration and size distribution of airborne hexavalent chromium in electroplating factories. Am. Ind. Hyg. Assoc. J. 58, 29-32.

Langard, S. (1990) One hundred years of chromium and cancer: a review of epidemiological evidence and selected case reports. Am. J. Ind. Med. 17, 189-215.

Lin, S. C., Tai, C. C., Chan, C. C. and Wang, J. D. (1994) Nasal septum lesions caused by chromium exposure among chromium electroplating workers. Am. J. Ind. Med. 26, 221-228.

Newitt, D. M., Dombrowski, N. and Knelan, F. H. (1954) Liquid entrainment: the mechanism of drop formation from gas or vapour bubbles. Trans. Inst. Chem. Eng. 32, 244-261. 
Pilacinski, W., Pan, M. J., Szewczyk, K. W., Lehtimaki, M. and Willeke, K. (1990) Aerosol release from aerated broths. Biotechnol. Bioeng. 36, 970-973.

Piotrowicz, S. R., Duce, R. A., Fasching, J. L. and Weisel, C. P. (1979) Bursting bubbles and their effect on the sea-to-air transport of $\mathrm{Fe}, \mathrm{Cu}$ and $\mathrm{Zn}$. Mar. Chem. 7, 307-324.

Sanz, P., Moline, J. L., Sole, D. and Corbella, J. (1989) Nasal septum perforation in chromate-producing industry in Spain. J. Occup. Med. 31(12), 1013.

Van Dusen, J. and Smith, J. W. (1989) Comparison of the effectiveness of bubble coalescence and foamed surfactant in controlling the acid mist formed by electrowinning cells. Am. Ind. Hyg. Assoc. J. 50(5), 252-256.

Van Grieken, R. E., Johansson, T. B. and Winchester, J. W. (1974) Trace metal fractionation effects between sea water and aerosols from bubble bursting. J. Rech. Atmos. 12, 611-620.

Wangwongwatana, S., Scarpino, P. V., Willeke, K. and Baron, P. A. (1990) System for characterizing aerosols from bubbling liquids. Aerosol Sci. Technol. 13, 297-307.

Zaki, N. (1990) Risk reduction in chromium emissions. Metal Finishing 88(6), 99-102. 